\title{
A MANEIRA DE FAZER HISTÓRIA DE MICHEL FOUCAULT: DIALOGANDO COM A HISTÓRIA DA SEXUALIDADE 1
}

\author{
José Antonio Miranda Sepulveda ${ }^{\mathrm{i}}$ \\ Denize Sepulveda ${ }^{\text {ii }}$
}

\begin{abstract}
Resumo: O presente artigo analisa a maneira de fazer história proposta por Michel Foucault, em especial a sua discussão sobre a genealogia como método histórico. Buscamos entender a crítica que o autor faz sobre a história teológica e teleológica, em que alguns historiadores demonstram a necessidade de buscar as origens dos acontecimentos e as descrevem de maneira linear. A nossa preocupação é entender os dispositivos utilizados por Foucault para construir a sua História da sexualidade. Para efeitos deste artigo, nos dedicaremos exclusivamente ao volume 1, cujo subtítulo é: a vontade de saber. Em tal livro, Foucault (1988) defende a tese de que o discurso, produzido na modernidade, sobre sexo, ao invés de reprimi-lo, acabou estimulando que se estabelecesse um valor mercantil para o sexo. Para isso, construímos este texto demonstrando a proposta foucaultiana de história em relação à origem das coisas, tendo como objeto a crítica à história universal. Como conclusão, discutimos a questão do poder tendo como foco a história da sexualidade.
\end{abstract}

Palavras-chave: Foucault; genealogia; história.

\section{MICHEL FOUCAULT'S WAY OF MAKING HISTORY: DIALOGUING WITH HISTORY OF SEXUALITY 1}

\begin{abstract}
This article analyzes the way of making history proposed by Michel Foucault, in particular his discussion of genealogy as a historical method. We seek to understand the criticism that the author makes about theological and teleological history, in which some historians demonstrate the need to search for the origins of events and describe them in a linear manner. Our concern is to understand the devices used by Foucault to build his History of Sexuality. For the purposes of this article, we will dedicate ourselves exclusively to volume 1 of the trilogy that carries this title, whose subtitle is: the will to know. In such a book, Foucault (1988) defends the thesis that the discourse, produced in modernity, about sex, instead of repressing it, ended up stimulating the establishment of a commercial value for sex. For this, we constructed this text demonstrating the Foucaultian proposal of history in relation to the origin of things, having as object the critique of universal history. As a conclusion, we discussed the issue of power focusing on the history of sexuality. Key words: Foucault, genealogy, history.
\end{abstract}

Key words: Foucault; genealogy; history.

\section{Introdução}

Michel Foucault (1988) alega que, em nossa época, existe a produção de um discurso que visa construir a sexualidade como um conjunto de saber/poder que almeja interferir nas formas de pensar e de conhecer o corpo e os prazeres. Essa alocução faria parte da tentativa do controle sobre os indivíduos, um 
controle que atuaria por meio da interdição e da repressão, mas principalmente pela produção da proliferação de discursos sobre as sexualidades. Portanto, a repressão sexual proposta pela burguesia em fins do século XVIII e início do século XIX acabou se tornando uma hipocrisia, pois, ao mesmo tempo que se estimulava essa repressão, havia um "[...] discurso destinado a dizer a verdade sobre o sexo, a modificar sua economia no real, a subverter a lei que o rege, a mudar seu futuro" (FOUCAULT,1988, p. 14). Assim, essa preleção sobre o sexo, que se desdobrou no discurso sobre a sexualidade, acabou sustentando um regime de poder-saber-prazer; e é justamente o funcionamento desse regime e suas razões de ser que o autor discute, em seu trabalho.

Foucault (2010a) construiu toda uma argumentação sobre o fazer da história que colocou em dúvida as formas tradicionais do método histórico. Dessa forma, para entender a história da sexualidade que ele elabora, é importante discutir a sua concepção de história. Com efeito, o objetivo deste artigo é desenvolver um debate sobre a forma diferenciada de fazer história desenvolvida por Foucault (2010a). Nossa intenção é expor a sua proposta genealógica da história a partir da sua crítica às formas tradicionais de história, em especial às formas que ele chama de teológicas de base teleológica. Dessa forma, para começar o texto, nos dedicaremos à crítica à busca de uma origem das coisas. Para tanto, o livro de sua autoria intitulado História da sexualidade 1: a vontade de saber será analisado, ou melhor, situaremos nessa obra algumas das propostas do autor, em relação a uma nova maneira de se fazer a história (FOUCAULT, 1988).

\section{A história e a origem das coisas}

Michel Foucault (2010a), ao propor uma diferente forma de fazer história, tece uma crítica a certa maneira de fazê-la, ao modelo que ele chama de teológica, no qual se buscava um telos para os acontecimentos e esses eram descritos de forma linear. A proposta do autor para se fazer história foi chamada por ele de genealogia, segundo a qual a singularidade dos acontecimentos está onde menos se espera e não na sua origem ou no seu fim. Uma importante crítica que Foucault (2010a) estabelece em relação à história teológica diz respeito à questão da neutralidade do historiador e do afastamento deste em relação ao seu objeto. Segundo o autor, na genealogia não se acredita na neutralidade nem no afastamento do historiador em relação ao seu objeto de pesquisa.

Finalmente, a última característica desta história efetiva. Ela não teme ser um saber perspectivo. Os historiadores buscam, na medida do possível, apagar o que pode revelar, em seu saber, o lugar de onde eles olham, o momento em que eles estão, o partido que eles tomam, o incontornável de sua paixão. O sentido histórico, tal como Nietzsche o entende, se sabe perspectiva, e não recusa o sistema de sua própria injustiça. Ele olha sob um certo ângulo, com o propósito deliberado de apreciar, de dizer sim ou não, de seguir todos os traços do veneno, de encontrar o melhor antídoto. Em vez de fingir um discreto apagamento diante daquilo que ele olha, em vez de ali buscar sua lei e de submeter a isso cada um de seus movimentos, é um olhar que sabe de onda olha, assim como o que olha. $\mathrm{O}$ sentido histórico dá ao saber a possibilidade de fazer no próprio movimento de seu conhecimento, 
sua genealogia. A wirkliche Historie efetua uma genealogia da história com a projeção vertical do lugar em que ela se sustenta. (FOUCAULT, 2010a, p. 274-275).

O conceito central da problemática levantada por Foucault (2010a, p. 274-275) são as formas de saber e a história, nessa a história, aparece como uma forma de saber. Tal forma vai variar de acordo com o referencial com que o historiador trabalha. Portanto, Foucault (2010a) vai criticar a forma do saber da história teológica e propor o saber genealógico como outra perspectiva de se escrever a história. Essa crítica do autor aparece de maneira explícita no seu livro História da sexualidade 1: a vontade de saber, em que Foucault (1988) descreve que, apesar de a história datar a origem de uma Idade da Repressão Sexual no século XVII, na verdade ela coincide com o desenvolvimento do capitalismo e faz parte da ordem burguesa; logo, uma série de acontecimentos possibilitou esse desenvolvimento.

Esse discurso sobre a repressão moderna do sexo se sustenta. Sem dúvida porque é fácil de ser dominado. Uma grave caução histórica e política o protege; pondo a origem da Idade de Repressão no século XVII, após centenas de anos de arejamento e de expressão livre, faz-se com que coincida com o desenvolvimento do capitalismo: ele faria parte da ordem burguesa. (FOUCAULT, 1988, p. 12).

Para Foucault (2010a), a história não é construída de uma forma linear, num esquema de causa e efeito, de ordem e progresso; e sugere que se observem, nos acontecimentos, aquilo que eles têm de agudo e singular. Para isso, o autor propõe acontecimentalizar a história, o que significa analisar o acontecimento de múltiplas formas. Para ele, o acontecimento está relacionado à noção de atualidade e, assim, interrogar a atualidade é problematizá-la como acontecimento. A questão posta por Foucault (2010a, p. 273) - “o que é a nossa atualidade?" - tem como consequência adotar a noção de acontecimento como indispensável a seu entendimento. Interrogar a atualidade é questioná-la como acontecimento, na configuração de uma problematização.

Para Foucault (2010a), acontecimento é sempre único e agudo e, por isso, está sempre rodeado por uma relação de forças, no acaso da vida. Ele não é gerado por uma única causa somente, que vai gerar uma consequência, pois sempre há uma multiplicidade de fatores interagindo para que se manifeste. Acontecimentos não são os grandes feitos, nem as grandes batalhas ou as grandes revoluções, tampouco ele é desenvolvido por grandes personagens. São as coisas singulares, que ocorrem no acaso, pela necessidade de estarmos vivos, que provocam o desenrolar dos acontecimentos. Assim, ele é produzido pelas pessoas comuns, que vivem a vida de todos os dias.

\footnotetext{
Acontecimento: é preciso entendê-lo não como uma decisão, um tratado, um reino ou uma batalha, mas como uma relação de forças que se inverte, um poder confiscado, um vocabulário retomado e voltado contra seus utilizadores, uma dominação que se enfraquece, se amplia e se envenena e uma outra que faz a sua entrada, mascarada. As forças que estão em jogo na história não obedecem nem a uma destinação nem a uma mecânica, mas ao acaso da luta. Elas não se manifestam com as formas sucessivas de uma intenção primordial; tampouco têm a aparência de um resultado. Elas surgem sempre no aleatório singular do acontecimento. Diferentemente do mundo cristão, universalmente tecido pela aranha divina, diferentemente do mundo grego, dividido, entre o reino da vontade e da
} 
grande besteira cósmica, o mundo da história efetiva conhece apenas um reino, no qual não há providência nem causa final, mas somente a "mão de ferro" da necessidade que sacode o copo de dados do acaso (FOUCAULT, 2010a, p. 273-274).

A partir do que foi dito, podemos perceber que atualidade e acontecimentos estão mutuamente enredados nas relações que estabelecem entre si. Assim, o autor enfatiza que a genealogia exige a minúcia do saber e da paciência; que ela não é feita dos grandes fatos, pelos grandes heróis, nem dos grandes erros saudáveis, "[...] mas de pequenas verdades inaparentes, estabelecidos por um método severo" (FOUCAULT, 2010a, p. 260).

Foucault (2010a) está chamando atenção para uma perspectiva de se fazer história e para aquilo que ele considera que deveria ser ultrapassado, ou seja, a história que trabalha com a origem das coisas; e defende uma nova maneira de se fazer história, que é a genealogia. Por isso, propõe a genealogia como método, dado que ela não se faz com a busca de sua origem, mas se detém nas meticulosidades e nos acasos dos começos. Assim, o "[...] genealogista tem necessidade da história para conjurar a ilusão da origem, um pouco como o bom filósofo tem necessidade do médico para conjurar a sombra da alma" (FOUCAULT, 2010a, p. 264). Para o autor, a genealogia não pretende mostrar que o passado está vivo no presente, mas evidenciar que, na raiz do que conhecemos e do que somos, não há absolutamente a verdade e o ser, mas a exterioridade de uma ruptura que faz surgir uma singularidade, que provoca analisar o caráter múltiplo dos acontecimentos (FOUCAULT, 2010a).

Por isso, no livro por nós analisado, Foucault (1988) diz que, para se compreender a história da sexualidade, deve-se levar em conta que o discurso produzido na história sobre a sexualidade se desenvolveu de maneira diferente através dos séculos.

\footnotetext{
A história da sexualidade, se quisermos centrá-la nos mecanismos de repressão, supõe duas rupturas. Uma no decorrer do século XVII: nascimento das grandes proibições, valorização exclusiva da sexualidade adulta e matrimonial, imperativos de decência, esquiva obrigatória do corpo, contenção e pudores imperativos da linguagem; a outra no século XX; menos ruptura, aliás, do que inflexão da curva: é o momento em que os mecanismos de repressão teriam começado a afrouxar: passar-se-ia das interdições sexuais imperiosas a uma relativa tolerância a propósito das relações pré-nupciais ou extramatrimoniais; a desqualificação dos perversos teria sido atenuada e, sua condenação pela lei, eliminada em parte; ter-se-iam eliminado em grande parte, os tabus que pesava sobre a sexualidade das crianças. Deve-se tentar seguir a cronologia desses procedimentos: as invenções, as mutações instrumentais, as remanescências. Mas, existe também o calendário de sua utilização, a cronologia de sua difusão e dos efeitos (de submissão ou de resistência) que eles induzem. Essas datações múltiplas, sem dúvida, não coincidem com o grande ciclo repressivo que se costuma situar entre os séculos XVII e XX. (FOUCAULT, 1988, p. 126).
}

Segundo Foucualt (1988) até o início do século XVII havia certa liberdade em relação às práticas sexuais. Tal cenário se modifica a partir da moral repressiva e castradora da sociedade vitoriana, no qual a sexualidade passa por um processo de silenciamento e é trancafiada ao quarto dos pais.

Diz-se que no início do século XVII ainda vigorava uma certa franqueza. As práticas não procuravam o segredo; as palavras eram ditas sem reticências excessiva e, as coisas, sem demasiado 
disfarces; tinha-se como o ilícito uma tolerante familiaridade. Eram frouxos os códigos da grosseria, da obscenidade, da decência, se comparados com os do século XIX. Gestos diretos, discursos sem vergonha, transgressões visíveis, anatomias mostradas e facilmente misturadas, crianças astutas vagando, sem incômodo nem escândalo, entre os risos dos adultos: os corpos "pavoneavam". (FOUCAULT, 1988, p. 9).

Outra diferença, apontada por Foucault (2010a), entre a história teológica e a genealogia é que a teológica está preocupada em localizar a causa que desencadeia os acontecimentos. A genealogia compreende o acontecimento primeiramente com uma história discursiva e, posteriormente, se volta para o não discursivo, ou seja, para a formação das práticas. Quando Foucault se volta para a história da sexualidade, para a "genealogia do homem do desejo", a pensa a partir de constantes mudanças, da Antiguidade até o momento atual. Nesse contexto, o autor valoriza a história das experiências. Tal valorização é uma resposta à história das mentalidades ${ }^{\mathrm{iii}}$, à história das ideias, pois essas correntes históricas valorizam o pensamento, a racionalidade, a totalidade, a perspectiva global em detrimento da experiência.

Essa apreciação também pode ser vista no livro ora avaliado, quando Foucault (1988) argumenta que o objetivo de sua investigação é mostrar como os dispositivos de poder se articulam ao corpo. Porém, essa busca não deve ser feita como uma história das mentalidades e sim como uma história dos corpos, pois esta não analisa somente a maneira pela qual os corpos foram vistos, mas como, através da experiência dos corpos, pode se perceber como sobre neles se investiu o que há de mais material e mais vivo.

Em todo o caso, o objetivo da presente investigação é, de fato, mostrar de que modo se articulam dispositivos, de poder diretamente ao corpo a corpo, a funções, a processos fisiológicos, sensações, prazeres; longe do corpo ter de ser apagado, trata-se de fazê-lo aparecer numa análise em que o biológico e o histórico não constituam sequência, como no evolucionismo dos antigos sociólogos, mas se liguem de acordo com uma complexidade crescente à medida em que se desenvolvam as tecnologias modernas de poder que tomam por alvo a vida. Não uma "história das mentalidades", portanto que só leve em conta os corpos pela maneira como foram percebidos ou receberam sentido e valor; mas "história dos corpos" e da maneira como se investiu sobre o que neles há de mais material, de mais vivo. (FOUCAULT, 1988, p. 165).

Além de Foucault (1988, p. 165) criticar a história das mentalidades, ele também faz uma crítica à história teológica e a uma linearidade sequencial característica do evolucionismo preconizado pelos sociólogos que pertencem àquela corrente da história e de certa forma, também, a uma maneira de se fazer história que se pretende universal.

\section{A questão da história universal}

Foucault (1983), no texto $O$ que é o Iluminismo ${ }^{i v}$ ?, parte do princípio de que não se pode elaborar uma história universal e critica essa maneira de fazer história. No texto $O$ que são as Luzes?, Foucault (2010b) valoriza o pensamento de Kant em relação a uma análise totalitária sobre a história, ou seja, sobre o afastamento de uma explicação universal dos acontecimentos, já que essa é uma questão debatida por ele, relativa à produção filosófica ocidental, que tenta enquadrar todo o pensamento filosófico presente sob sua 
lógica universalizante. Foucault (2010a) critica uma forma de elaboração da história que trabalha com um ponto de vista supra-histórico, ou seja, com uma história que se mostre atemporal e universal, que explique todos os acontecimentos com sua verdade ocidental e que se pretenda objetiva.

Em História da sexualidade 1: a vontade de saber, essa crítica aparece explícita e às vezes implícita em várias passagens, o que demonstra que a apreciação de Foucault (2010a) sobre a história que se pretende universal não está presente só na esfera teórica, mas também em sua própria maneira de fazer história. Logo na introdução do referido livro, tal forma de fazer história se faz presente, pois Foucault (1988) explana que há mais de um século nossa sociedade fala, prolixamente, sobre seu próprio silêncio acerca da sexualidade; questiona o fato de continuarmos a enfatizar que nossa sexualidade é reprimida desde o passado mais próximo, o que continua a acontecer no presente; e que, no momento atual, chegamos a enfatizar que nosso sexo é negado e considerado, ainda, um pecado.

\begin{abstract}
Através de que hipérbole conseguimos chegar a afirmar que o sexo é negado, a mostrar ostensivamente que o escondemos, a dizer que o calamos - e isso formulando-o através de palavras explícitas, procurando mostrá-lo em sua realidade mais crua, afirmando-o na positividade de seu poder e de seus efeitos? Seria legítimo, certamente, perguntar por que, durante tanto tempo, associou-se o sexo ao pecado - e, ainda, seria preciso ver de que maneira se fez essa associação e evitar dizer de forma global e precipitada que o sexo era "condenado" - mas seria também, preciso perguntar por que hoje em dia nos culpamos tanto por ter outrora feito dele um pecado? Através de que caminhos acabamos ficando "em falta", com respeito ao nosso sexo? E acabamos sendo uma civilização suficiente singular para dizer a si mesma que, durante muito tempo e ainda atualmente tem "pecado" contra o sexo por abuso de poder? De que maneira ocorre esse deslocamento que, mesmos pretendendo liberar-nos da natureza pecaminosa do sexo, atormenta-nos com um grande pecado histórico que teria consistido, justamente, em imaginar essa natureza falível e em tirar dessa crença efeitos desastrosos? (FOUCAULT, 1988, p. 15).
\end{abstract}

De uma forma implícita, ao fazer esses questionamentos e análises, Foucault (1988) defende que ainda nos prendemos a explicações universais do passado para fazermos uma análise do presente. Essa questão do presente é importante para o autor, pois ele quer entender o que, no presente, faz sentido em uma reflexão filosófica. Como aquele que pensa faz parte desse presente? Como o sujeito seleciona o acontecimento a ser analisado e como é afetado por ele? Como o sujeito constitui e é constituído, nesse processo? Foucault (1983) entende que essas questões fazem parte de um processo histórico que concerne o pensamento, o conhecimento, a filosofia; e que o pensador, o filósofo, ele mesmo faz parte desse processo.

Ainda relacionado à questão do presente, Foucault (1988) enfatiza que as investigações históricas do presente sobre a sexualidade e das que virão a ser feitas devem estar voltadas menos para uma teoria do que para uma analítica do poder, para que se possa fazer uma determinação dos instrumentos que permitam analisar a questão do poder.

Ora, parece-me que essa analítica só pode ser constituída fazendo tabula rasa e liberando-se de uma certa representação do poder, que eu chamaria - veremos adiante por que - de "jurídico-discursiva". É essa concepção que comanda a temática da repressão quanto a teoria da lei, enquanto constitutiva do desejo. Em outros termos, o que distingue uma análise da outra, a que é feita em termos de repressão dos instintos e a que se faz em termos de lei do desejo é, certamente, a maneira de conceber 
a natureza e a dinâmica das pulsões; não é a maneira de conceber o poder. Uma como a outra recorre a uma representação comum do poder que, segundo o emprego que faz dele e a posição que se lhe reconhece quanto ao desejo, leva a duas consequências opostas : seja a promessa de uma "liberação", se o poder só tiver um domínio exterior sobre o desejo, seja à afirmação - se for constitutivo do próprio desejo - de que sempre já se está enredado. Não devemos imaginar, aliás, que essa representação seja própria dos que colocam o problema das relações entre o poder e o sexo. De fato, ela é muito mais geral; pode-se encontrá-la com frequência nas análises políticas do poder, e se enraíza sem dúvida muito longe na história do Ocidente. (FOUCAULT, 1988, p. 92-93).

Foucault (1988, p. 92-93), além de valorizar a história do tempo presente em relação à análise do poder e do sexo, volta novamente a criticar uma história ocidental que se pretenda universal e atemporal. Foucault (1983) entende a questão do presente como um acontecimento filosófico, ao qual pertence o filósofo que fala. E a questão do acontecimento de fato é valorizada por Foucault (1983), já que ele mesmo valoriza a experiência, que para ele se mostra pela via do acontecimento, com o qual ele procura entender a relação entre poder, saber e sujeito.

Para Foucault (1988), a questão do acontecimento na conduta sexual é uma experiência, seja ela acidente ou desvio, déficit ou excesso - a experiência é apta a despertar os efeitos mais distintos, no decorrer de toda uma vivência.

O acontecimento mais discreto na conduta sexual - acidente ou desvio, déficit ou excesso - é supostamente, capaz de provocar as consequências mais variadas, ao longo de toda a existência; não há doença ou distúrbio para os quais o século XIX não tenha imaginado pelo menos uma parte de etiologia sexual. Dos maus hábitos das crianças às tísicas dos adultos, às apoplexias dos velhos, às doenças nervosas e as degenerescências da raça, a medicina de então teceu toda uma rede de causalidade sexual. É possível que nos pareça fantástico. O princípio do sexo "causa de tudo e de nada" é o inverso teórico de uma exigência técnica: fazer funcionar numa prática de tipo científica os procedimentos de uma confissão que, ao mesmo tempo, deveria ser total, meticulosa e constante. Os perigos ilimitados que o sexo traz consigo justificam o caráter exaustivo da inquisição a que é submetido. (FOUCAULT, 1988, p. 75).

A confissão é um tipo de discurso e, segundo Foucault (1983), a atualidade do discurso vai caracterizar a filosofia como discurso da modernidade e sobre a modernidade, pois o discurso do filósofo não tem mais que ficar ligado ao passado, à cultura clássica, e sim se conectar com o seu tempo. Dessa forma, a história da sexualidade, para o autor, deve ser feita com base em uma história dos discursos.

O século XIX desloca a confissão ao integrá-la a um projeto de discurso científico; ela não tende mais a tratar somente daquilo que o sujeito gostaria de esconder, porém daquilo que se esconde ao próprio sujeito, e que só se pode revelar progressivamente e através de uma confissão da qual participam o interrogador e o interrogado, cada um por se lado. O princípio de uma latência essencial à sexualidade permite articular a coerção de uma confissão difícil a uma prática científica. É bem preciso arrancá-la, e à força, já que ela se esconde. (FOUCAULT, 1988, p. 75-77).

Na realidade, Foucault (1988) estava interessado em trabalhar com a história das experiências, dos modos de saber, de poder e da ética. Ele queria entender como as experiências interagem interrogando como o discurso, o saber, o poder e o fazer se articulam entre si. Em relação à questão do poder, Foucault (1988) 
expõe a sua concepção, defendendo que tal questão está difusa no campo social e presente em tudo, e faz a relação disso com as questões do discurso e da sexualidade.

\title{
A questão do poder
}

Foucault (1988) refuta a figura do poder como simplesmente repressor, negador do sexo, que é uma força selvagem, uma pulsão a ser domesticada. Ele quer entender como o poder, o saber e o prazer se articulam. Essa imagem do poder como opressor da liberdade nos concede acolher a sua vigência, pois o seu alcance pode ser ainda maior. O discurso jurídico e as leis não mais simbolizam o poder de maneira mais geral; este extrapolou seus limites a partir do século XVIII, criando novas tecnologias de dominação. Nós somos controlados e normatizados por múltiplos processos de poder. Essa visão do poder também é vital para uma história da sexualidade. Em relação aos múltiplos processos de poder sobre a sexualidade destacamos o pensamento de Foucault (1988) no livro História da sexualidade 1: a vontade de saber.

\begin{abstract}
A Idade Média tinha organizado, sobre o tema da carne e da prática da confissão, um discurso estreitamente unitário. No decorrer dos séculos recentes, essa relativa unidade foi decomposta, dispersada, reduzida a uma explosão de discursividades distintas, que tomaram forma na demografia, na biologia, na medicina, na psiquiatria, na psicologia, na moral, na crítica política. E mais: o sólido vínculo que vinculava a teologia moral da concupiscência à obrigação da confissão (o discurso teórico sobre o sexo e sua formulação na primeira pessoa), foi rompido ou, pelo menos, distendido e diversificado: entre a objetivação do sexo nos discursos racionais e o movimento pelo qual cada um é colocado na situação de contar seu próprio sexo produziu-se, a partir do século XVIII, toda uma série de tensões, conflitos, esforços de ajustamento, e tentativas de retranscrição. Não é, portanto, simplesmente em termos de extensão contínua que se deve falar desse acréscimo discursivo; ao contrário, deve-se ver aí a dispersão dos focos de onde tais discursos são emitidos, a diversificação de suas formas e o desdobramento complexo da rede que os une. Em vez da preocupação uniforme em esconder o sexo, em lugar do recato geral da linguagem, a característica de nossos três últimos séculos é a variedade a larga dispersão dos aparelhos inventados para escutar, registrar, transcrever e redistribuir o que dele se diz. (FOUCAULT, 1988, p. 40).
\end{abstract}

O poder, para Foucault (1988), provém de todos os lados; portanto, as relações sociais são dinâmicas, móveis e mantêm ou destroem grandes diagramas de dominação. Essas correlações de poder são relacionais e interagem sempre com inúmeros pontos de resistência que são, ao mesmo tempo, alvo e apoio do poder. Dessa forma, as resistências devem ser vistas sempre no plural.

Foucault (1988) sugere também a existência de quatro prescrições de prudência para se analisar uma história da sexualidade. São elas: as regras de imanência, as regras de variações contínuas, as regras do duplo condicionamento e as regras da polivalência. As regras de imanência levam em conta como a produção de saberes se liga com as relações de poder e os focos de saber-poder. Nas regras das variações contínuas, as relações de poder não são estáticas, não há dualidade opressor/oprimido. Para as regras do duplo condicionamento, os focos locais de poder são condicionados por estratégias globais e vice-versa, ambos se apoiando mutuamente um no outro. Para a regra da polivalência, a importância está na tática dos discursos. O discurso não reflete a realidade, o poder e o saber se articulam no discurso. O que interessa 
não é o discurso isolado, mas uma multiplicidade de discursos, que implicam táticas diversas. Através do discurso disseminado, o poder é produzido. A sexualidade é o correspondente a uma prática discursiva desenvolvida vagarosamente e que é chamada pelo autor de scientia sexualis (FOUCAULT, 1988).

As características fundamentais a essa sexualidade não traduzem uma representação mais ou menos confundida pela ideologia, ou um desconhecimento induzido pelas interdições; correspondem às exigências funcionais do discurso que deve produzir sua verdade. No ponto de intersecção entre uma técnica de confissão e uma discursividade científica, lá onde foi preciso encontrar entre elas alguns grandes mecanismos de ajustamento (técnica de escuta, postulado de causalidade, princípio de latência, regra da interpretação, imperativo de medicalização), a sexualidade foi definida como sendo, "por natureza", um domínio penetrável por processos patológicos, solicitando, portanto, intervenções terapêuticas ou de normalização; um campo de significações a decifrar; um lugar de processos ocultos por mecanismos específicos; um foco de relações causais infinitas, uma palavra obscura que é preciso, ao mesmo tempo, desencavar e escutar. É a "economia" dos discursos, ou seja, sua tecnologia intrínseca, as necessidades de seu funcionamento, as táticas que instauram, os efeitos de poder que os sustêm e que veiculam - é isso, e não um sistema de representações, o que determina as características fundamentais do que eles dizem. A história da sexualidade - isto é, daquilo que funcionou no século XIX como domínio de verdade específica - deve ser feita, antes de mais nada, do ponto de vista de uma história dos discursos. (FOUCAULT, 1988, p. 78).

Foucault (1988) fala de quatro táticas globais de dominação, constituintes do dispositivo da sexualidade, a saber: a histerização do corpo da mulher, a pedagogização do corpo da criança, a socialização das condutas de procriação e a psiquiatrização do prazer perverso. Para o autor, essas táticas acabam produzindo uma nova tecnologia sexual que surgiu no século XVIII designando uma relação entre degenerescência, hereditariedade e perversão (FOUCAULT, 1988).

Com efeito, a análise, em termos de poder, não deve postular uma determinada forma de lei ou uma forma universal de uma dominação. O que devemos compreender primeiro, em relação ao poder, diz respeito à multiplicidade de correlações de forças imanentes ao domínio em que se exercem as práticas constitutivas da sua organização. Através de lutas e disputas intensas, tais práticas transformam, reforçam e invertem a multiplicidade de correlação de forças, ou seja, as estratégias em que essas relações se desenvolvem se encontram institucionalizadas nos aparelhos estatais, na formulação das leis, nas hegemonias estabelecidas socialmente.

A análise em termos de poder não deve postular, como dados iniciais, a soberania do Estado, a forma da lei ou a unidade global de uma dominação; estas são apenas e, antes de mais nada, suas formas terminais. Parece-me que se deve compreender o poder primeiro, como a multiplicidade de correlações de força imanentes ao domínio onde se exercem e constitutivas de sua organização; o jogo que, através de lutas e afrontamentos incessantes as transforma, reforça, inverte; os apoios que tais correlações de força encontram umas nas outras, formando cadeias ou sistemas ou ao contrário, as defasagens e contradições que as isolam entre si; enfim, as estratégias em que se originam e cujo esboço geral ou cristalização institucional toma corpo nos aparelhos estatais, na formulação da lei, nas hegemonias sociais. A condição de possibilidade do poder, em todo caso, o ponto de vista que permite tornar seu exercício inteligível até em seus efeitos mais "periféricos" e, também, enseja empregar seus mecanismos como chave de inteligibilidade do campo social, não deve ser procurada na existência primeira de um ponto central, num foco único de soberania de onde partiriam formas derivadas e descendentes, é o suporte móvel das correlações de força que, devido à desigualdade, induzem continuamente estados de poder, mas sempre localizados e instáveis. (FOUCAULT, 1988, p. 102-103). 
O dispositivo da sexualidade é uma forma de poder que estabeleceu o sexo como uma verdade que age sobre o indivíduo e que atravessou o domínio da carne, dos corpos, dos prazeres. O autor opõe essa ideia ao antigo dispositivo da aliança, que determinava o proibido/permitido por meio dos casamentos e das leis. O dispositivo da sexualidade se desenvolveu na classe burguesa e está intrinsecamente ligado à ascensão dessa classe social. As classes populares, submetidas, antes, somente ao dispositivo da aliança, passaram a ser submetidas também ao dispositivo da sexualidade, por causa da hegemonia da burguesia, que detinha doravante o poder econômico.

Assim, a burguesia se vê forçada a permitir algumas coisas: restringe as sexualidades ilegítimas a lugares onde possam dar lucros, pois, numa época em que o trabalho é muito explorado, as energias não podem ser desperdiçadas nos prazeres. Segundo Foucault (1988), tal repressão é chamada de hipótese repressiva; mas, o autor questiona essa concepção e desenvolve uma nova tese, alegando que, para algumas explicações funcionarem, elas não podem ser vistas como verdadeiras, já que qualquer hipótese deve estar submetida a um conjunto múltiplo de fatores que refutem as explicações unitárias e universais. O seu projeto, portanto, é a investigação da maneira como se constitui a experiência em que os indivíduos se reconhecem como sujeitos de uma sexualidade que se abre para conhecimentos diversos e se articula num sistema de regras e coerções. Sua análise é sobre os homens como sujeitos sexuais produtores de história, expostos a uma multiplicidade de fatores que interagem entre si.

\section{Considerações finais}

A proposta deste texto foi tentar entender a forma de fazer história de Michel Foucault (2010a, 1988). Defendemos aqui que a sua metodologia parte de uma premissa que discorda de uma pretensa história universal, pois a história, vista de tal forma, reduz as análises a explicações unitárias, como se fosse possível estabelecer uma única verdade condizente com todo o processo de relações históricas. Dessa forma, o fazer história se constrói como atemporal e dogmático.

Para Foucault (2010a), um ponto fundamental se apresenta em relação à metodologia de análise histórica, com sua crítica à concepção de origem. Tal apreciação reforça a tese que questiona a rigidez da cronologia histórica. Isso permite ao autor desenvolver suas explicações livre das amarras temporais que, para ele, são construções que, por vezes, distorcem uma melhor compreensão do processo. Portanto, Foucault (2010a) defende que, em uma genealogia, uma determinada explicação não necessariamente se encontra no início ou no fim de um processo histórico. Assim, Foucault (2010a) defende a ideia de que a história não é movida por uma cadeia de relações de causa e efeito ou por um motor econômico dicotomizado entre o bem e o mal ou dominantes e dominados; ela é construída a partir de uma 
multiplicidade de fatores, que interagem construindo um conjunto de motivações que, de alguma forma, justificam um acontecimento ou possibilitam uma interpretação.

Tal interpretação só é possível, segundo o autor, mediante diferentes análises da multiplicidade de discursos produzidos sobre um determinado tema de relevância histórica, apesar de que essa importância, para o autor, só existe se, de alguma maneira, for construído um discurso sobre um dado assunto. Portanto, a própria construção do que é história passa por uma disputa de poder que define o que é e o que não é relevante.

Dessa forma, para Foucault (1988), não é possível fazer história, ou melhor, não é possível fazer ciência, sem levar em conta as relações de poder estabelecidas pela própria ciência, em que os cientistas, em um profundo jogo, disputam, definem o que é científico e, para que isso ocorra, o autor entende que houve um longo processo definido pelas relações de poder. Ao mesmo tempo, para se compreender o processo histórico, é necessário se compreender todo o mecanismo de poder que regimenta um determinado período. Tal mecanismo não é predeterminado e, portanto, não é cronologicamente definido por períodos. Foucault (2010a) não acredita na possibilidade de se fazer história de forma linear, porque os tempos também são definidos por uma multiplicidade de fatores que se estabelecem a partir de relações de poder. Com efeito, Foucault (2010a) critica de forma intensa as formas sequenciais ou cronológicas de história.

O que podemos compreender é que Foucault (1988), quando trata da questão da sexualidade, entendeu o processo histórico que a constituiu como um mecanismo de poder e de controle dos corpos. Ele identifica, em sua genealogia da sexualidade, momentos distintos de disputa, em uma correlação de forças, em que se desenvolveram diferentes relações de poder-saber-fazer com relação ao sexo. Houve, portanto, forças que entenderam que o controle dos corpos era fundamental para a manutenção das estruturas de poder.

Foucault (1988) destaca a Igreja Católica da Idade Média e a burguesia do século XIX como as forças hegemônicas que defenderam determinados padrões de conduta sexual, todavia ele entende também que esse processo, que acabou por se transformar em uma forma de se esconder o problema sexo, acabou estimulando-o e criando todo um conjunto de relações determinadas por explicações morais, tanto de caráter religioso quanto de caráter científico. Essa postura constrói um modelo de normal e patológico que reproduz, portanto, toda uma estrutura de relações de poder. É importante ressaltar que essa análise não se baseia em um conjunto linear de explicações que partiriam do poder da Igreja Católica, na Idade Média, até o poder da burguesia, no século XIX. Para o autor, tratam-se de processos distintos, movidos por uma multiplicidade de fatores que atendem às questões de diferentes períodos históricos. Vale salientar, ainda, que as correlações de força também são diferentes em cada momento e representam forças distintas, que se desenvolvem a partir da constituição de novos contextos (FOUCAULT, 1988). 
Assim, a questão da não linearidade, aliada a uma visão genealógica da história, como utilizada pelo autor, apresenta não só uma nova perspectiva da história da sexualidade, mas também uma nova construção metodológica de como se fazer história. Tal questão coloca, sem dúvida, o livro História da sexualidade 1: a vontade de saber como uma das mais importantes reflexões acerca do problema da sexualidade nas sociedades contemporâneas e um dos principais exemplos de aplicação metodológica da história genealógica (FOUCAULT, 1988).

\section{Referências}

FOUCAULT, Michel. História da sexualidade 1: a vontade de saber. Rio de Janeiro: Graal, 1988.

FOUCAULT, Michel. Nietzsche, a genealogia, a história. In: Ditos \& escritos II: arqueologia das ciências e história dos sistemas de pensamento. Rio de Janeiro: Forense Universitária, 2010a.

FOUCAULT, Michel. O que é o Iluminismo? Paris: Collège de France, 1983. Curso transcrito por Katharina Von Bülow.

FOUCAULT, Michel. O que são as Luzes? In: Ditos \& escritos II: arqueologia das ciências e história dos sistemas de pensamento. Rio de Janeiro: Forense Universitária, 2010b.

GONDRA, José Gonçalves (Org.). Pesquisa em história da educação no Brasil. Rio de Janeiro: DP\&A, 2005.

LE GOFF, Jacques. A história nova. São Paulo: Martins Fontes, 1990.

MARCONDES, Danilo. Iniciação à história da filosofia: dos pré-socráticos a Wittgenstein. Rio de Janeiro: Za har, 2001.

Recebido em: 17/06/2020

Aceito em: 03/08/2020

\section{Notas}

\footnotetext{
${ }^{\text {i }}$ Professor do Programa de Pós Graduação em Educação da Universidade Federal Fluminense. Professor Adjunto da Faculdade de Educação da Universidade Federal Fluminense. Líder do Diretório de Pesquisa e Estudos Os Impactos do Conservadorismo na Educação Brasileira. Vice líder do Diretório de Pesquisa e Estudos Gêneros Sexualidades e Diferenças nos Vários EspaçosTempos da História e dos Cotidianos. Coordenador do Observatório da Laicidade na Educação da Universidade Federal Fluminense. E-mail: jamsepulveda2@yahoo.com.br Rio de Janeiro ORCID: http://orcid.org/0000-0003-4460-7704

ii Coordenadora Adjunta do Programa de Pós Graduação em Educação: Processos Formativos e Desigualdades Sociais da Universidade do Estado do Rio de Janeiro na Faculdade de Formação de Professores. Professora Adjunta do Departamento de Educação da Universidade do Estado do Rio de Janeiro na Faculdade de Formação de Professores. Líder do Diretório de Pesquisa e Estudos Gêneros Sexualidades e Diferenças nos Vários EspaçosTempos da História e dos Cotidianos. Vice líder do Diretório de Pesquisa e Estudos Os Impactos do Conservadorismo na Educação Brasileira. Colaboradora do Observatório da Laicidade na Educação da Universidade Federal Fluminense. E-mail: denizesepulveda@hotmail.com Rio de Janeiro. ORCID: http://orcid.org/0000-0001-9049-5200
} 
iii A chamada História das mentalidades é um ramo da teoria da história. É considerada uma análise de tipo mais profundo da História, pois visa compreender as grandes alterações nas formas de pensar e agir do Homem ao longo dos tempos. Inscreve-se no chamado tempo longo (a longa duração), de teor essencialmente estrutural e que atua nos diversos fatores de uma sociedade. Tem implicações na política, na sociedade, na economia, na cultura, na filosofia e na religião. Enquadra cada complexo históricogeográfico e determina-o profundamente, não obstante, por sua própria natureza, e procura discernir o que pertence especificamente a uma época e o que constitui permanência. Tal ramo da Teoria da História tem sua origem na chamada Escola dos Annales.

iv Iluminismo é um conceito que sintetiza uma ampla variedade de tradições filosóficas, sociais, políticas, correntes intelectuais e atitudes religiosas. É o ápice de um movimento intelectual que se inicia no Renascimento e que, somado ao empirismo inglês, produziu um modelo de análise comum que identifica um determinado movimento intelectual. O uso do termo Iluminismo então, na forma singular, justifica-se a partir certas tendências gerais comuns de pensamento: a ênfase nas idéias de progresso e perfectibilidade humana, assim como a defesa do conhecimento racional como meio para a superação de preconceitos e ideologias tradicionais. O Iluminismo é, para sintetizar, uma atitude geral de pensamento e de ação. Os iluministas admitiam que os seres humanos são capazes de tornar este um mundo melhor - mediante introspecção, livre exercício das capacidades humanas e do engajamento político-social. 